\title{
Out of school opportunities for science and mathematics learning: Environment as the third educator
}

\author{
Valeria M. Cabello ${ }^{1}$ and Vesna Ferk Savec ${ }^{2}$ \\ 1 Pontificia Universidad Católica de Chile, Facultad de Educación, Chile \\ ${ }^{2}$ University of Ljubljana, Faculty of Education, Slovenia
}

\begin{abstract}
Out-of-school environments offer a unique opportunity for experiental learning which transcends the role of educational resources and teachers. This article introduces the special topic of out-of-school learning in science and mathematics education. First, we present the theoretical underpinnings from the movement towards crossing the boundaries of school in educational practices and broadening educational spaces. We continue with the key facets of out-of-school learning through a constructivist approach, aided by the concept of mediation environments as the third educator from a socio-material perspective. Furthermore, we focus our discussion on a selection of articles from this special number as an international overview on out-ofschool learning. In the conclusion section, we discuss the gaps that the following works fill, as well as new questions that arise in the area. The closing remarks highlight the promotion of active learning in students, considering the role of the environment as the third educator.
\end{abstract}

Keywords: out-of-school, lifelong learning, science education, mathematics education

Contact: vmcabello@uc.cl

DOI: https:/ doi.org/ 10.31129/LUMAT.6.2.353

\section{Introduction}

Science education has an important role in the development of citizenship and global responsibility for sustainable development (Ratcliffe \& Grace, 2003). In this regard, the idea that science learning transcends the boundaries of the school classroom has become increasingly accepted. Hence, outdoor activities might become powerful learning experiences for connecting students with nature and socio-scientific issues (Beames, Higgins, \& Nicol, 2012). Indeed, in some countries outdoor education has been formalized as a promotor of interdisciplinary and experiential learning from early years education to higher education (Christie, Higgins, \& Nicol, 2015). Nonetheless, outdoor education is just one type of out-of-school learning and it does not exclude other possibilities. 


\section{Facets of out-of-school learning}

Usually, out-of-school opportunities are associated with outdoor education. However, outdoor education is only one form of out-of-school learning, and also many other activities, such as visiting exhibitions, museums, camps, etc. are considered to be outof-school education.

On the one hand, outdoor education offers structured opportunities for students to identify hazards, calculate related risks and decide the significance of a risk in order to determine and implement precautions. In this regard, this type of education promotes students' self-awareness and taking greater responsibility for their own and others' safety (Office for Standards in Education, 2004). Even so, there is a fine line between recreational and educational objectives in outdoor education (Allison \& Telford, 2005).

On the other hand, education through exhibitions, galleries or museums usually has an educational purpose clearly defined and recognised by teachers but not always by leisure visitors. Furthermore, these educational spaces need to be intrinsically motivating at every step of the interaction, have an educational purpose, and respond well to the diversity of learners (Allen, 2004), not just to those with prior scientific interest.

Modern science education needs to consider that the taught concepts, procedures and attitudes or values are relevant to students, their communities and contexts. This means that the objectives of science education contribute to living a better life, and to the protection of the environment, culture and society in particular. This is based on the assumption that each learner is a citizen independent of their age and that science education for responsible citizenship is a commitment for all (European Comission, 2015).

It is evident that science education has turned away from having its' only purpose in orienting students' scientific vocations. Nowadays, we understand that science education should be contextually relevant and pertinent to all students, which leads to new challenges in terms of teaching and learning, and new pedagogical scenarios. Thus, we can state that the contents learned within the classroom are important if they are relevant outside the classroom, too. Therefore, the interrelation between the diversity of knowledge and the development of individuals as citizens is the protagonist of the educational opportunities that cross the boundaries of classrooms. This focus in science education guides the learners to think scientifically, carry out 
inquiries and scientific experiments and communicate science in order to learn. This is called experiential learning. Consequently, educational spaces outside the classroom invite us, as educators, to value the usefulness of being able to reason in an evolving world, and the need for this reasoning to be connected with the environment (Izquierdo \&Aymerich, 2005).

\section{Mediational opportunities}

Mediational opportunities in education are interactive activities that teachers organize in order to support learners in developing new content, skills, procedures or attitudes. The environment brings mediational opportunities for learning, through the framework of socio-material perspective (Impedovo, Delserieys-Pedregosa, J égou, \& Ravanis, 2017). Through this perspective, the educational opportunities, the educators, learners and the environment are inseparable as educational agents. Thus, this perspective considers social elements and experiences provided by the environment as a "living” educator. Hence, out-of-school education brings new life to interactions for learning (Strong-Wilson \& Ellis, 2007).

Fraser and Wien (2001) identified eight key principles for creating meaning through the use of space: aesthetics, transparency, active promotion of learning, flexibility, collaborational processes, reciprocity, bringing the outdoors in, and relationships (Strong-Wilson \& Ellis, 2007). By implementing these principles the environment becomes the third educator. An important aspect to consider in this approach is how to maintain a flexible balance between providing structure for interactions to mediate learning, whilst encouraging learners to free exploration (Tarini \& White, 1998).

According to the socio-material perspective the environment is inclusive, learners are partners and collaborators in their learning and understand their inherent responsibilities as global citizens. Thus, out-of-school learning experiences, from this perspective, promote students' sense of agency and have an influence in their world. This involves children contributing not only to making the environment safe, through for example using equipment and resources in an appropriate way, but also through giving a sense of the creation of communities and culture within the environment (ACECQA, 2016). 


\section{Critical findings of out-of-school experiences for science and mathematics education: contributions of this special issue}

This special issue highlights the relevance of out-of-school learning opportunities from two main perspectives. The first perspective considers the teachers' views and perceptions about the facilitators and constraints of out-of-school learning, and likewise the process of changing these views among science student teachers and inservice teachers. The second perspective constitutes of studies exploring science and mathematics learning opportunities in applied out-of-school settings such as science camps, exhibitions, Olympiads and photography galleries.

This special number of LUMAT assembles eight international articles on educational experiences related to out-of-school learning. Henrikson, from Finland, collects primary school teachers' conceptions of using out-of-school settings as an educational resource for science teaching and learning. She highlights the motivational role of these experiences in contributing to students' interest for science. She also presents teachers' perceptions regarding the organizational and economic aspects of some out-of-school opportunities such as outdoor experiences. The work ends with the researchers' concern for the relevance given by the teachers to the scientific knowledge in out-of-school settings. Similarly, Hopper and Köller from Norway describe student teachers' understanding regarding an out-of-school chemistry-lab, through talking sessions, video observation and interviews. They concentrated on the teachers' expectations which were in general positive. The study focused on the relevance and worthiness of this out-of-school experience as a future pedagogical practice.

Bustamante from Chile goes one step further, asking herself about the extent to which teachers' perceptions about education in non-formal spaces - more specifically, the museums - might change. She found ontological changes in teachers' perceptions and epistemological changes in the way they conceived how knowledge and learning is constructed in science.

The next articles are based on the work of Finnish researchers. Halonen \& Askela present an experience focused on science camps, combining the perceptions of children and families and the impact of children's gender as well as prior interest on chemistry-camps to the perceived relevance. They show that this type of out-of-school learning experience is particularly relevant when there is a low prior interest in science. Another experience from science camps is presented by Nuora and Välisaari, 
however, with students from $6^{\text {th }}$ to $9^{\text {th }}$ grades, and with a focus on inquiry in nature. They demonstrate that it is possible to introduce chemistry and biology concepts in a more authentic context through science camps.

Laherto's paper moves into another type of out-of-school learning experience: an exhibition for illustrating the Nano-world. He points out the role of informal educational spaces to promote public engagement in scientific issues, discussing suggestions for improving exhibitions from a visitor-oriented educational perspective. Mutanen \& Askela report on an Olympiad experience, focusing on the educational relevance of a science competition and the training of highly skilled students, exploring also gender differences.

Finally, Meier, Hannula and Toivanen from Finland and Norway present a work on expanded perception through outdoors photography. They found that this experience had a positive impact on the teacher students' perceptions of the use of photography for teaching mathematics, which will be relevant for their future work as innovative teachers. This finding resonates with Hopper and Köller, who also found that student teachers had an increased interest in applying out-of-school learning in their future work after having experienced those by themselves in teacher education.

\section{Conclusion}

Although the themes presented in this special issue are not intended to be exhaustive of out-of-school experiences, they provide an opportunity for LUMAT readers who wish to research or explore out-of-school educational spaces to do so. Considering that the environment mediates in educational processes as the third educator as well as the resources and the teacher him/ herself. The experiences collected in this special issue open a window for learning more about the diverse forms and alternatives of out-of-school learning from the beginning of the school years to the professional development of science and math teachers. Additionally, in the future it would be interesting to study new questions, such as how the experiences of variation of teacher guidance in experiential activities support diverse forms of student engagement, taking into account that active learning, promoted for instance, by out-of-school experiences, increases student performance and reduces inequalities. 


\section{Acknowledgements}

This special issue was possible thanks toJ ohannes Pernaa's commitment to managing the flow of the articles and our reflections as invited editors. We also thank the CONICYT PAI AR project 821320002 and LUMA Centre Finland, for inspiring our international collaboration.

\section{References}

ACECQA. (2016). The environment as the third educator. In Australian children's education \& care quality authority (Ed.), National Quality Standard (pp. 3). Australia: National Childcare Accreditation Council.

Allen, S. (2004). Designs for learning: Studying science museum exhibits that do more than entertain. Science education, 88(S1), S17- S33.

Allison, P., \& Telford, J . (2005). Turbulent times: outdoor education in Great Britain 19932003. J ournal of Outdoor and Environmental Education, 9(2), 21.

Beames, S., Higgins, P., \& Nicol, R. (2012). Learning outside the classroom: Theory and guidelines for practice: Routledge.

Christie, B., Higgins, P., \& Nicol, R. (2015). Curricular outdoor learning in Scotland. Routledge international handbook of outdoor studies, 113.

European Comission. (2015). Science Education for Responsible Citizenship. Retrieved from Brussels: http:/ / ec.europa.eu/ research/ swafs/ pdf/ pub_science_education/ KINA-26-893-EN-N.pdf

Fraser, S., \&Wien, C. A. (2001). Authentic childhood: Experiencing Reggio Emilia in the classroom. The Canadian J ournal of Infancy and Early Childhood, 8(4), 75.

Impedovo, M. A., Delserieys-Pedregosa, A., J égou, C., \& Ravanis, K. (2017). Shadow formation at preschool from a socio-materiality perspective. Research in Science Education, 47(3), 579-601.

Izquierdo i Aymerich, M. (2005). Hacia una teoría de los contenidos escolares. Enseñanza delas Ciencias, 23(1), 111- 122.

Office for Standards in Education. (2004). Outdoor education: Aspects of good practice. Retrieved from http:/ / dera.ioe.ac.uk/ id/ eprint/ 4914

Ratcliffe, M., \& Grace, M. (2003). Science education for citizenship: Teaching socioscientific issues: McGraw-Hill Education (UK).

Strong-Wilson, T., \& Ellis, J . (2007). Children and Place: Reggio Emilia's Environment As Third educator. Theory Into Practice, 46(1), 40- 47. doi:10.1080/00405840709336547

Tarini, E., \& White, L. (1998). Looking in the mirror. In C. Edwards, L. Gandini, \&G. Forman (Eds.), The hundred languages of children: The Reggio Emilia approachAdvanced reflections (2nd ed., pp. 375- 404). Westport, CT: Ablex. 